\title{
Metadisciplina na Inter-relação entre o Design e a Educação
}

\section{Metacourse in the Interconnection between Design and Education}

\author{
SILVA, Anna Lúcia S. V.; Professora Doutora; Universidade Federal do Ceará \\ lilu@dau.ufc.br \\ CALVET, Lya B.; Graduanda; Universidade Federal do Ceará \\ calvetlya@gmail.com \\ MOREIRA, Alline A. B.; Graduanda; Universidade Federal do Ceará \\ adeallinealbuquerque@gmail.com \\ CARNEIRO, Alexander C.; Graduando; Universidade Federal do Ceará \\ alexanderccarneiro@gmail.com \\ FURTADO, Victor S. M.; Graduando; Universidade Federal do Ceará \\ victorsmfurtado@gmail.com
}

\begin{abstract}
Resumo
O artigo contempla aspectos de uma ampla pesquisa-ação sobre metadisciplina, uma disciplina que se constrói enquanto é ministrada. Em sua totalidade, a pesquisa abrange a confluência da Semiótica, Educação e Design em um cenário de experiências didáticas no curso de Design desde 2014. O aspecto apreciado aqui identifica e analisa os sentidos que o Design agrega à investigação e à educação, em proposições de codesign, metaprojeto, metadesign e HCD (Design centrado no ser humano) por meio de um estudo de caso da metadisciplina em Projeto IV, realizada em 2017. O objetivo é a construção de conhecimentos que consideram repertórios e interesses individuais e propicia a criação de valores coletivos mais equânimes. Como resultado verificamos que os fundamentos do Design aplicados, na pesquisa e na sala de aula, fortalecem a autonomia, a autogestão e a coerência entre o que se estuda e o que se faz.
\end{abstract}

Palavras Chave: pesquisa através do Design; metadisciplina; ensino e aprendizagem.

\section{Abstract}

This paper contemplates aspects of a broad action research about metacourse, a course that is constructed while it is administered. In its entirety, this research encompasses the confluence of Semiotic, Education and Design in a scenario of didactic experiences at a Design course since 2014. The aspect valued in this paper identifies and analyzes the meanings of what Design adds to the research and education in propositions of codesign, metaproject, metadesign and HCD (Human-Centered Design) through a case study of metacourse in Project IV, held in 2017. The objective is to build knowledge that considers repertoires and individual interests and propiciates the creation of more equitable collective values. As a result, we verified that the foundations of Design applied, in research and in the classroom, strengthen the autonomy, the self-management and the coherence between what is studied and what is done.

Keywords: research through Design; metacouse; teaching and learning. 


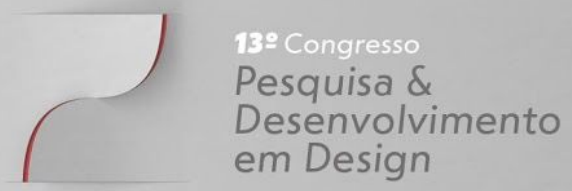

Artigo Completo

\section{Introdução}

Metadisciplina é uma disciplina que se reflete. "Meta" traz o sentido de autorreflexão, de transcendência "[...] volta da consciência do espírito, sobre si mesmo, para seu próprio conteúdo por meio do entendimento, da razão" (MORAES, 2010, p. 29). Refletir-se implica tanto uma reflexão racional sobre si quanto um espelhamento. Na reflexão sobre si surgem as perguntas: como pensar uma disciplina acadêmica juntamente com quem está envolvido nela (professores, estudantes, monitores)? Como incluir conteúdos de interesse dos participantes na abordagem da ementa? Com que métodos desenvolver um processo pedagógico que engendra a si mesmo? Como o design pode colaborar em sua realização? Refletir-se, também significa o espelho que é voltado aos estudantes que se tornam corresponsáveis no desenvolvimento da disciplina, no reconhecimento de seus interesses e na consequente construção de seu próprio conhecimento.

A metadisciplina nasce no Departamento de Arquitetura e Urbanismo, no curso de Design em 2014. Sua origem se dá por influência da proposta pedagógica da disciplina "Didática I" (2014.2), da Faculdade de Educação (FACED - Universidade Federal do Ceará), assistida por uma professora do Curso de Design e aplicada nas disciplinas "Métodos de Representação" (2014.2); "Semiótica" (2015.1, 2016.1 e 2017.1) e "Projeto de Produto IV" (2015.2 e 2016.2), todas do curso de Design da UFC. A cada experiência, uma nova elaboração e mais perguntas.

No segundo semestre de 2016 houve uma nova proposição na FACED-Faculdade de Educação da UFC, que recebe a proposta da metadisciplina como parte de um experimento didático por uma engenhosa junção de estudantes de graduação, de pós-graduação e cinco professores doutores nas áreas da educação e do design. A partir desta experiência foi identificada a necessidade de dar início a uma pesquisa formal sobre metadisciplina que tem início em 2017: "Metadisciplina: um enfoque semiótico". Nesta etapa, a pesquisa tem o objetivo principal de ampliar conhecimentos sobre os processos de ensino e de aprendizagem na confluência das áreas da semiótica, educação e design e é desenvolvida por meio do estudo de caso da disciplina de Semiótica em 2016.1 e de uma pesquisa-ação na mesma disciplina em 2017.1. Os resultados de 2017 enfatizam a fundamentação semiótica, o processo criativo e a organização triádica dos parâmetros trabalhados. A partir deles, o grupo de pesquisa ganha uma nova abordagem: mais alunos interessados em participar e uma maior complexidade com a ampliação do estudo de caso, que passa a incluir a disciplina de Projeto de Produto 4 e a ênfase direcionada aos aspectos do design.

No âmbito educacional, novos paradigmas acompanham as transformações do século XXI e são traduzidos em teorias que giram em torno da aprendizagem colaborativa (TORRES, 2004, CAMPOS et al, 2003) e da pesquisa-ação (TRIPP, 2005; THIOLLENT, 1985; TOLEDO \& JACOBI, 2013) entre outras diversas pesquisas que contribuem no objetivo de considerar os indivíduos como agentes ativos na construção do conhecimento, como uma prática de liberdade (ACASO, 2015, FREIRE, 1967, 2015; SAVIANI, 1995).

Cada aluno carrega consigo vivências singulares e, por vezes, até mesmo conhecimentos prévios a respeito de um assunto abordado em sala de aula. Esses repertórios costumam ser negligenciados em prol da concepção de um conteúdo predeterminado que resulta em um exercício anti reflexivo (ACASO in ACASO et. al, 2015), tanto para o docente quanto para o discente. $O$ conhecimento é reproduzido quando poderia ser produzido, criado e compartilhado.

No contexto do design, ocorre a transição de um modelo fundamentado na uniformização global dos objetos, característica das correntes funcionalistas, para um cenário no qual o design 
reflete sobre si mesmo, seu alcance e objetivos (KRIPPENDORF 2000, MARGOLIN, 2004, MANZINI, 2017). Como enfatiza Papanek em seu clássico "Design for the Real Word" (PAPANEK, 1972) a cultura projetual passa da produção de artefatos - especialmente para o consumo - a uma crescente ampliação de seu campo de abrangência, com um novo contorno aos significados que Ihe são conferidos - o projeto admite que a maneira com que vemos, convivemos e interpretamos um dado produto vai muito além de uma série de critérios objetivos e que é preciso levar em conta aspectos de necessidades sociais, ambientais e do comportamento humano (MANZINI, 2008).

Com a admissão do design enquanto discurso, cujos artefatos ativam múltiplas redes de usuários que lhes conferirão contextos subjetivos, a prática se torna muito mais aberta e passa a trabalhar com interesses reais, não criados ou idealizados. O design é visto como um mediador entre sistemas, simultaneamente criando e simplificando complexidades: o projeto visualiza as redes de relações que um produto ou serviço contempla e estabelece pontes entre estas através de metodologias colaborativas e abordagens holísticas.

Esta roupagem do design, ao girar em torno da totalidade, pede uma imersão profunda dos profissionais da prática nas redes supracitadas, transformando usuários em participantes ativos da própria prática projetual: trata-se do design centrado no ser humano (Human Centered Design HCD, IDEO, 2009). O HCD nasce como uma crítica ao consumismo, mas se desenvolve (principalmente como modus operandi) muito além dele, em outro paradigma, em detrimento da competição e do consumo, a favor da colaboração e do compartilhamento. Uma forma direta e objetiva de enfrentar e dialogar com a escala global, considerando sua amplitude. Nesse sentido o design e a educação se entrelaçam ao valorizar a importância colaborativa na construção de conhecimento e na resolução de problemas. Dessa forma, encaixamos a metadisciplina no panorama atual como uma proposta de ensino, de aprendizagem e de design.

A metodologia da pesquisa-ação (TRIPP, 2005; TOLEDO e JACOBI, 2013, THIOLLENT, 1985) é aplicada desde o início da metadisciplina com aprimoramentos contínuos que se dão em ciclos alternados de experiências em sala de aula, documentação, análises e novas proposições aperfeiçoadas.

Como uma pesquisa-ação interdisciplinar, o projeto se justifica por sua relevância em organizar, relacionar, analisar e aplicar diferentes saberes com o intuito de aperfeiçoar as dinâmicas pedagógicas. Com a abertura das atuações docentes na construção compartilhada de conhecimentos em sala de aula, as perspectivas do protagonismo discente se expandem em processos criativos e em métodos direcionados à co-responsabilidade de transmissão e apreensão das informações, onde os interesses subjetivos dialogam com as ementas, a educação se adequa aos meios de comunicação e sistemas de interação no desenvolvimento de novas metodologias. Levantamos a hipótese de que a metadisciplina é um paradigma na qualificação do ensino e da aprendizagem, que favorece a troca de saberes, a construção horizontal de conhecimentos, a autonomia do estudante e um maior interesse deste nos assuntos acadêmicos.

\section{Coerências entre forma e conteúdo}

Tendo em vista a problemática da contradição entre a atual conjuntura e os parâmetros adotados no âmbito do ensino, percebemos a necessidade de uma proposição que flexibilize as relações em sala de aula e possibilite uma autonomia do conhecimento. Como aponta Acaso (2015), uma classe é um sistema de representação e, como tal, tem potencialidade para assumir 
diversos sentidos. Na pesquisa, o objetivo é alcançar essa pluralidade de significados que, acreditamos, como hipótese, se encontra no protagonismo estudantil. Segundo Rancière (2008), não se trata de um exercício de transformação, mas de reconhecimento:

[...] Em todos os lugares há pontos de partida e pontos de virada a partir dos quais aprendemos coisas novas, se dispensarmos primeiramente o pressuposto da distância, depois, o da distribuição de papéis e, em terceiro, o das fronteiras entre os territórios. Nós não precisamos transformar espectadores em atores. Nós precisamos é reconhecer que cada espectador já é um ator em sua própria história e que cada ator é, por sua vez, espectador do mesmo tipo de história. (RANCIÈRE, 2008)

Quando professores e alunos são definidos como espectadores e atores, simultaneamente, é possível enxergá-los como sujeitos iguais na construção e da reconstrução do saber (Freire, 2015), o que caracteriza a classe como uma série de relações horizontais. As experiências e interesses pessoais devem ser trazidos à luz e, com estes, a constatação da singularidade de cada um. A diferença, então, torna-se o ponto de partida para tornar as aulas mais instigantes e produtivas através de reflexões, questionamentos e debates.

(...) a dialogicidade verdadeira, em que os sujeitos dialógicos aprendem e crescem na diferença, sobretudo no respeito a ela, é a forma de estar sendo coerentemente exigida por seres que, inacabados, assumindo-se como tais, se tornam radicalmente éticos (FREIRE, 2015, p. 59).

O processo de tomada de decisão é inerente à metadisciplina. Uma vez que sua participação influi diretamente na condução da disciplina, uma constante reflexão por parte do aluno acerca de sua atuação no contexto referido permeia toda a trajetória.

No que diz respeito ao design, a apreensão do projeto como uma construção dinâmica surge gradualmente à medida em que as aulas são realizadas. $O$ design, como um campo de inovação social em que competências específicas se complementam em uma apreensão holística dos eventos, incorpora o exercício colaborativo aliado ao pensamento crítico, característico dos processos sistêmicos dos campos em questão. As teorias se transformam em prática. $\mathrm{Na}$ proposição da metadisciplina cada participante é fundamental na construção de um processo constantemente auto-observado. Esta estrutura pode ser transferida ao processo de projeto e favorecer a idiossincrasia em métodos individuais e inovar como pesquisa através do design.

\section{Fundamentos do Design na pesquisa da metadisciplina}

O Design compõe um dos eixos teóricos que fundamentam a metadisciplina juntamente com a Semiótica e a Educação. Experimentações no âmbito acadêmico em um curso de Design ofereceram à pesquisa premissas de abordagens do Design que se complementam e configuram uma lógica da inter-relação entre design e metadisciplina que pode ser entendida tanto na pesquisa como em aplicações da metadisciplina em diferentes disciplinas, não específicas do curso de design. 


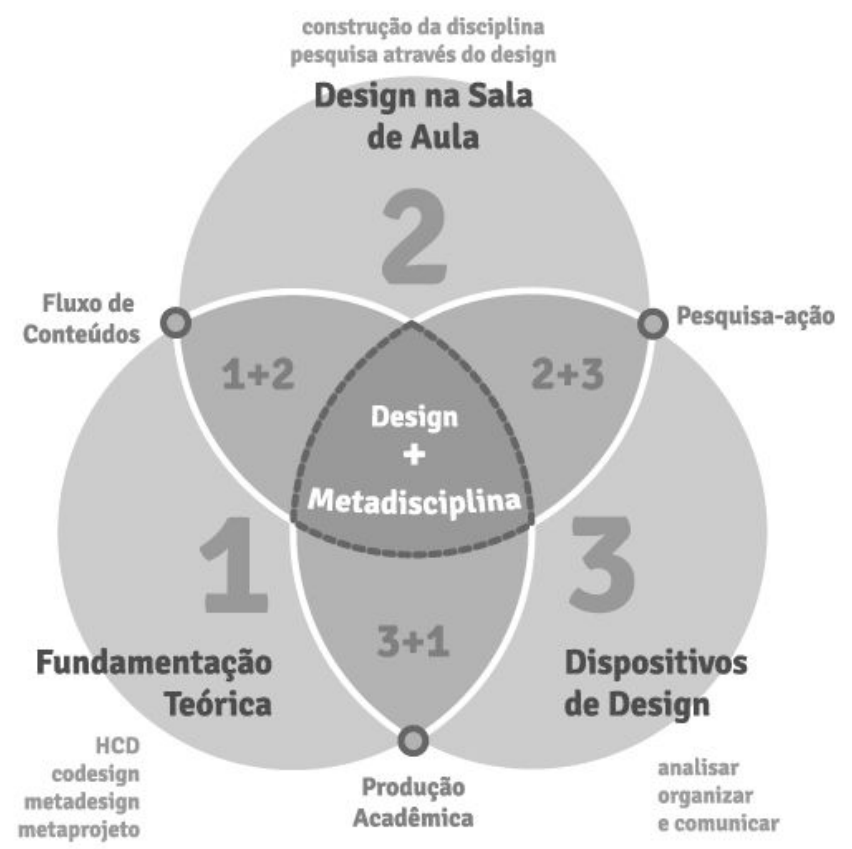

Fonte: Os autores (2017)

Tendo em vista esta grande rede que é estabelecida no ambiente de sala de aula entre alunos-alunos, professores-alunos e estes dois grupos com o mundo e a sociedade, a metadisciplina desenvolve os trabalhos científicos não considerando-os como um objeto ou "coisa" final, mas sim como um trânsito entre natureza, homem e pensamento, onde as transformações e mudanças de práticas projetuais e sociais são uma mediação para toda a expansão atual do design e desta mesma sociedade (LATOUR, 2008).

Subsequente a este olhar do designer como mediador de elaboração e extensão do homem, o design como discurso trata do que não se finaliza na própria manifestação física e/ou virtual de um produto projetado, e sim nas implicações sociais, culturais, econômicas e políticas através das quais o projeto, em todo o seu potencial, pode causar impactos em uma realidade, transformando-a. "Design é a defesa de uma causa. Onde as pessoas falam sobre o design, ele torna-se político. O design é mais efetivo quando incrustado na mesma comunidade que exige participação no futuro que ele realiza". (KRIPPENDORF, 2000, p.94)

Tal escala de resolução de problemas é ratificada na fala de Manzini, que elenca a conectividade como ferramenta de suma importância para o campo de ensino e pesquisa em design ao aliar-se à colaboração e apresenta o codesign como "processos altamente dinâmicos, atividades criativas e proativas e atividades complexas de design". (MANZINI, 2017, p. 63) 
Esse tipo de posicionamento, em consequência, abre espaço para pesquisas abertas, que integram pontos de vistas de contextos distintos de maneira otimizada ao alimentar o diálogo com a comunidade, seja acadêmica ou relativa ao campo de conhecimento, resguarda a pluralidade dos diversos pontos de vista e a coletividade dos processos colaborativos.

Ao abraçar a amplitude da ação projetual, o campo do design passa por um movimento de autorreflexão que é apropriado na metadisciplina. O termo "metadesign" é, então, incorporado como ferramenta de projeto e de processo de construção de conhecimento, como um meio de compreender a teia complexa de elementos que percorrem a atividade didática.

\begin{abstract}
Essa acepção reflexiva alude à própria etimologia do termo: desde a Metafísica de Aristóteles, o termo "meta-" aplica-se a um movimento reflexivo de autoconhecimento, ou de auto observação: utilizar meios de um campo para considerar o próprio campo. [...] Por outro lado, o prefixo "meta", palavra grega, significa "além", "após", "a seguir", "depois de", "na sequência", "uma série", significados ligados à ideia de movimento de ponto-a-ponto, de transposição (VASSÃo, 2010, p.19).
\end{abstract}

A valorização dos múltiplos pontos de vista é uma máxima do Design Centrado no Ser Humano, ou HCD: Human-Centered Design, como uma ferramenta metodológica para gerar alternativas de projeto e resolução de problemas, também incorporado à metadisciplina. De acordo com IDEO:

A razão pela qual esse processo é chamado de "Centrado no Ser Humano" é que ele começa pelas pessoas para as quais estejamos criando a solução. O processo do HCD começa por examinar as necessidades, desejos e comportamentos das pessoas cujas vidas queremos influenciar com nossas soluções. Procuramos ouvir e entender o que querem, a chamada 'lente do desejo'. Enxergamos o mundo através desta lente durante as várias etapas do processo de design. (IDEO, 2013, p.5)

A lógica do HCD permite que equipes multidisciplinares trabalhem em consonância, essencial na construção de qualquer projeto. Ao tornar essa realidade possível, cria-se a possibilidade da construção e concepção de ideias mais originais, com análises de pontos de vista distintos. Além disso, a importância do espaço criativo e a delimitação de tempo em prazos previstos são outras ferramentas do HCD. O primeiro propicia o contato visual com os instrumentos de pesquisa e o segundo incentiva os participantes a mirarem seus objetivos em uma linha de tempo previamente planejada.

Ouvir (Hear), Criar (Create) e Implementar (Deliver) constituem a tríade do Design Centrado no Ser Humano. No primeiro momento, o HCD supõe métodos qualitativos, ações que buscam conhecer mais profundamente as características de determinados grupos, demandas e problemas. Este é o modo de dar atenção às pessoas envolvidas, perceber seus anseios e características que as tornam únicas. Na sala de aula essa etapa escuta o aluno, seus interesses, seu repertório sobre determinado assunto conciliado à ementa. Também é o momento de buscar consenso em relação à estrutura da disciplina, cronograma e formas de avaliação, o metaprojeto da disciplina. É durante essa fase que muitos pressupostos são revistos e há o ampliamento das descobertas com relação às ideias e as concepções dos participantes. Depois de todos os dados coletados, chega o momento de pôr em prática o pensamento abstrato e elaborar sínteses e interpretações das informações reunidas na primeira etapa. A partir disso é possível descrever aquelas demandas concretas recolhidas anteriormente e transformá-las em insights mais universais e passíveis de solução. Transportando esse momento para a metadisciplina, é quando se realizam experimentações e atividades que figuram o entendimento do conteúdo definido na primeira etapa. Especificamente no curso de Design corresponde ao desenvolvimento de projetos. 
Finalmente, a etapa três consiste em efetivar as melhores ideias, entender como torná-las possíveis. É necessário que as soluções implantadas sejam viáveis, bem executadas e que permaneçam a longo prazo. Além disso, essa fase requer a elaboração de protótipos que possam interagir com o mundo real e diminuir, assim diminuindo as chances de que todo o trabalho feito anteriormente não seja em vão. Melhoramentos são a máxima da etapa de implementação, por configurar configurando assim um processo contínuo para que haja proatividade na sedimentação da solução a ser implantada. Na metadisciplina, essa etapa final corresponde a uma reflexão sobre todo processo, uma avaliação e a apresentação dos resultados.

Todas as referências no âmbito do design descritas acima são fundamentos na aplicação da metadisciplina por suas proposições comuns de participação e consideração imprescindível das pessoas no contexto de construção e partilha do conhecimento.

\section{$4 \quad$ O aqui e agora do design em sala de aula}

Inter-relações entre os alunos na etapa inicial de definição de conceitos e entendimento teórico da metadisciplina proporcionam um melhor entendimento dos vários âmbitos que um assunto ou problemática podem ter, o que indica as diversas soluções, aplicações e possíveis transformações. Na pesquisa nosso objeto de estudo está diretamente vinculado a conteúdos de design, mas nosso objetivo é encontrar as formas que o design pode ser entendido e aplicado na didática em outras áreas de conhecimento.

É a partir dessa noção de pluralidade interdisciplinar e de problemáticas variadas que é proposto aos alunos se reconhecerem como os construtores e organizadores diretos dos assuntos abordados na disciplina, considerando questões sociais. Os docentes e discentes se encontram assim mais aptos a discernir que a elaboração de respostas para as mais diversas perguntas são construídas por eles próprios como indivíduo inseridos em uma realidade coletiva, que não se encerra entre as quatro paredes habituais de uma sala de aula.

A sala de aula é um ambiente de reflexão que precisa ser ampliado. É no reconhecimento do cotidiano, a partir de imersões na cidade como pesquisa de campo, no olhar atento que está presente, que o aluno reconhece a si mesmo como agente, integrado ao meio, onde ambos podem ser redescobertos constantemente. Nesse sentido, a metadisciplina funciona como um ensaio antropológico em que o aluno se observa, se insere, se educa, se transforma e reconhece seu alcance social.

Sob uma visão latouriana, ao tomar o modo de pensar e o fazer científico como objeto de estudo e a localização destes dois elementos embebidos pela rede e pelo social, explicita-se ainda mais o fato de o conhecimento científico se tratar das ligações entre as pessoas. Isso se reflete na construção do nosso coletivo, tanto sob um prisma comunitário ou urbano quanto pautado em uma linha de raciocínio dentro da prática de design. Fazer ciência não significa, então, desvelar um mundo de coisas independentes do homem, mas relatar e reorganizar as articulações em um coletivo (KÖHLER, BAUM, 2013, p.148).

No entendimento de que alunos e professores compreendem a importância da pluralidade de visões a complexidade é acolhida a partir de uma perspectiva de resolução de problemas com o emprego do design, "fazer design que tome a forma de pesquisa em design para, por fim, gerar conhecimentos de design" (MANZINI, 2017).

Uma equipe de design não consegue produzir o conhecimento de design requerido para cada projeto individual na modalidade tradicional design-como-pesquisa. Portanto, é 
necessário desenvolver um repositório de conhecimento de design no qual o conhecimento necessário possa ser rapidamente aplicado quando e onde for necessário (MANZINI, 2017, p.53).

Além de tornar acessível para toda uma equipe esse conhecimento, a forma de construção do nosso mundo sob uma ótica concreta e de sentido também parte de um modo de design de fazer pesquisas (MANZINI, 2017).

O conceito de metadesign, adotado no conjunto de referenciais metodológicos e teóricos na metadisciplina, traz também os conceitos de complexidade, dinâmica e sistema. Optamos por fazer uso de uma definição de complexidade que ateste a escolha metodológica da não-redução do conteúdo. Estes conceitos levam em consideração a elaboração de modelos teóricos de representação, a criação de "uma imagem coesa, sintética e coerente" (VASSÃO, 2010, p.31) da realidade com a qual se pretende lidar. Isto permite que seja possível aplicar uma mesma estrutura de pensamento para diferentes situações, ou ainda que esta representação seja capaz de abarcar as mudanças inerentes à realidade que se analisa que é, por sua natureza, dinâmica.

Com base nesta compreensão, percebemos que lidar com um conteúdo programático complexo requer uma atitude que não o reduza simplesmente. Uma estrutura rígida de procedimentos determinados a priori também haveria de fracassar, por não ser capaz de absorver sua dinâmica. Assim, como estratégia didática, adotamos uma proposta aberta e flexível apoiada em uma plataforma que se propõe a lidar com o cenário volúvel heterogêneo da realidade. 0 metaprojeto (MORAES, 2010), metodologia do design que também é apropriada na metadisciplina e na pesquisa, propõe essa plataforma e pressupõe uma miríade de variáveis, problemas indistintos e soluções que não são finais, mas sustentáveis. O mesmo ocorre na metadisciplina: um aprendizado fechado não é efetivo quando se lida com múltiplos contextos. Há de se propor uma estrutura que suporte tais contextos a fim de condensar o processo em um resultado satisfatório, seja este um produto (no caso do projeto de design) ou a aprendizagem (no caso da disciplina).

Outra referência metodológica do design em grande evidência na pesquisa e na metadisciplina é o codesign (MANZINI, 2017; IDEO, 2013). No processo de codesign o sentido de cocriação e de cooperação no processo de projeto abrange "processos altamente dinâmicos" como metodologias de construção de consenso e processos complexos interconectados, frequentemente contraditórios; "atividades criativas e proativas" que abrangem iniciativas dos participantes e a criatividade como propulsora de diálogos sociais alimentados por novas ideias; "atividades complexas de design" que demandam ferramentas específicas de design para tornar situações e ideias complexas tangíveis e comunicáveis (MANZINI, 2017, p.63).

\footnotetext{
Pesquisas que produzem visões e propostas, em geral adotam métodos originais, empregando ferramentas e habilidades próprias à cultura e à prática do designer. Referimos-nos a isso como pesquisa através do design. (...) neste caso o conhecimento produzido ser implícito e integrado no design, mas deve ser explícito, discutível, transferível e combinável (MANZINI, 2017, p.54).
}

Outro aspecto do design na metadisciplina implica na síntese, organização e comunicabilidade do entendimento do processo e dos conteúdos. As proposições dos alunos são traduzidas em signos (gráficos, protótipos, textos, tabelas, listas, etc.), por meio de atividades criativas. Este aspecto contempla tanto o entendimento individual, como organização do próprio pensamento, como os processos de comunicação nas equipes de trabalho. Os modos diversificados de produção criativa de signos, gera uma conexão entre a construção cognitiva e sua disseminação. Métodos que incitam a criatividade viabilizam fluidez e reverberam não somente 
nos processos de raciocínio individual, mas na morfologia da organização de grupos, como fluxos naturais no sentido da autogestão.

A metadisciplina se encontra atualmente com uma tradição de pesquisa consolidada nos princípios semióticos, associada ao progressivo aperfeiçoamento da pesquisa-ação, fundamentada no metaprojeto e no metadesign, e integrada aos inclusivos codesign e HCD, o que permite deduzir que esta plataforma de fundamentos e combinações metodológicas está aberta ao acolhimento de novos métodos que possam surgir em seu desenvolvimento.

\section{$5 \quad$ Estudo de caso}

A fim de retratar a aplicação da metadisciplina em um contexto de ensino de Design, este artigo toma como estudo de caso os processos criativos desenvolvidos na cadeira de Projeto de Produto 4 (PP4), no segundo semestre de 2017. Para sua compreensão, é preciso mencionar a fase conceitual que assenta os conteúdos propostos pela ementa. Em um primeiro momento, uma vez que a metadisciplina é embasada na colaboração (Torres, 2004), foi verificado se havia um interesse consensual dos alunos na metadisciplina. Com a aceitação, é iniciada a discussão em torno das bases do metaprojeto: sistemas, dinâmica e complexidade. As professoras lançam os termos e pedem que os alunos contribuam para a construção de conceitos e definições. Este primeiro exercício possibilita uma reflexão mais aberta a respeito dos temas, ainda sem o referencial teórico. Já a partir desse momento, é empregada a "lente do desejo" que o HCD (IDEO, 2009) pressupõe. Essa reflexão é afunilada através do estudo aprofundado dos conceitos de metaprojeto e metadesign, que agrega, além destas referências prévias, textos trazidos pelos próprios alunos, no intuito de tangenciar suas áreas de interesse. A partir das discussões, o tema do projeto é definido coletiva e consensualmente: cidade.

Essa fase é sintetizada em um conjunto de habilidades que a turma deseja adquirir ao longo da disciplina. A habilidade síntese é "Deliberadamente criar discurso através do design e ser apto a desenvolver o projeto de um sistema considerando sua complexidade". É decidido em conjunto, também, como vamos organizar e compartilhar as informações e as formas de avaliação. As notas são baseadas nas apresentações de processo e na escrita de diários de classe individuais. Os diários compreendem uma pasta no Google Drive em que cada aluno passa a alimentar, diariamente, um documento em que descreve suas apreensões, indagações e pensamentos, de forma livre, acerca dos temas trazidos em sala. Estes documentos podem ser acessados por qualquer participante, o que permite interlocução, até mesmo a incorporação de pensamentos de um diário em outro, de modo que os processos criativos são constantemente enriquecidos a partir de uma troca de ideias que permeia toda a disciplina. Além disso, os alunos se alternam para a construção de uma "memória" - ao longo de cada aula, um membro da turma toma notas dos eventos e, posteriormente, os sintetiza de modo a resguardar os dados coletados para consulta futura e garantir a comunicação com os alunos que faltaram.

A fase prática tem início com uma pergunta: "Que problemas você vê na cidade?". Cada aluno, então, expõe sua problemática depois de um percurso/pesquisa de campo individual - e traz para aula o aspecto da cidade que deseja projetar. 0 próximo passo é definir um caminho projetual que acolha os interesses individuais e favoreça a composição de grupos de trabalho com interesses similares. Por meio da construção de infográficos grupos de três alunos categorizam os problemas e temáticas levantados individualmente e buscam convergências que apontem uma organização da turma por áreas de interesse. Ao final desse exercício, são formados os grupos para a execução dos projetos. É importante observar que, mesmo com a divisão da sala, os grupos 
continuam trocando referências bibliográficas e metodologias nas aulas dedicadas à exposição do processo.

Figuras 2, 3 e 4 - Sequência Cronológica de Projeto de Produto IV
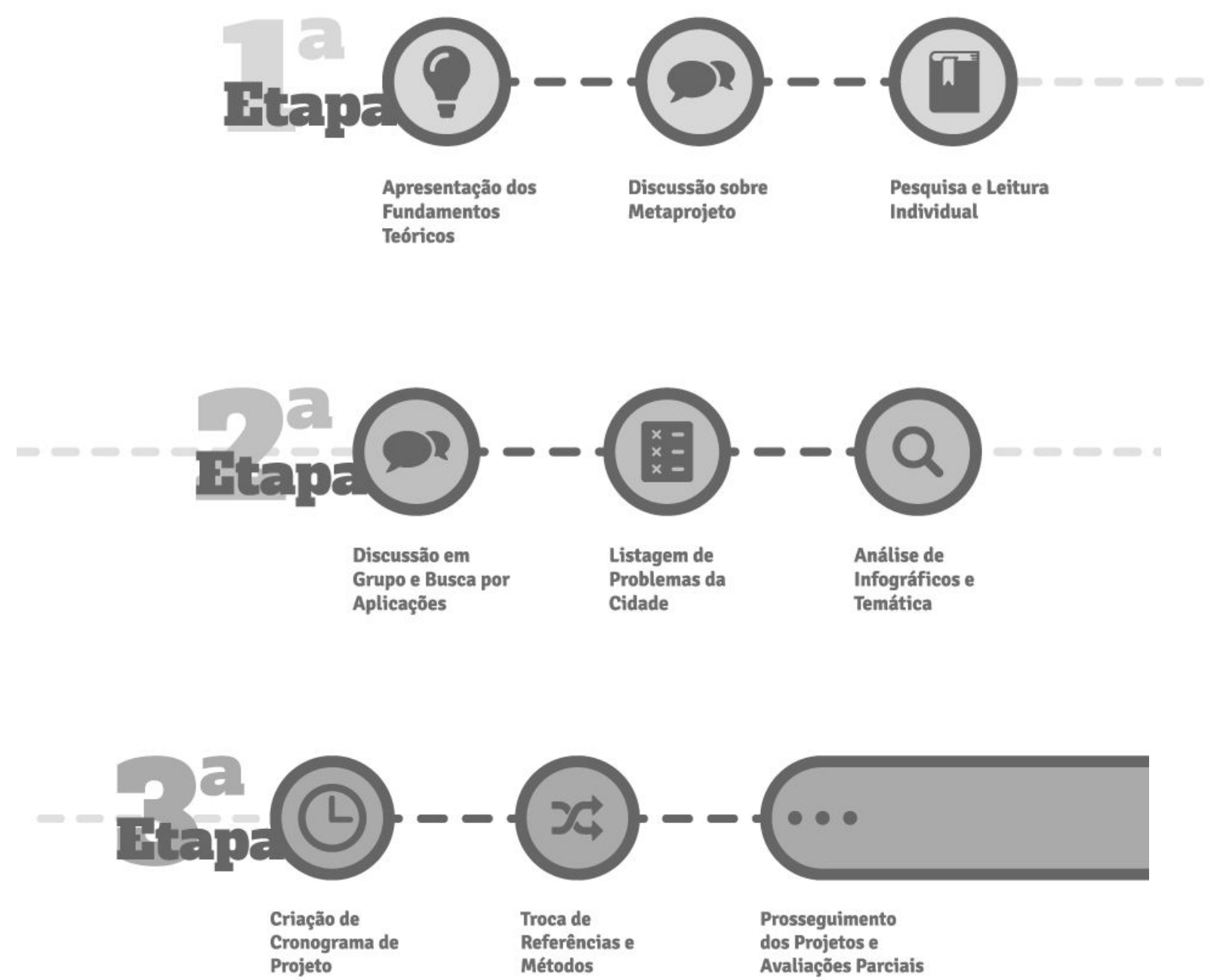

Fonte: Os autores (2017)

Foram formados dez grupos com diferentes configurações. Os diversos métodos que a turma utiliza para lidar com a autogestão podem ser visualizados nos exemplos de duas equipes de trabalho: o grupo A é permeado pela coletividade, enquanto o grupo B possui caráter individual.

O grupo A tem uma organização especial, uma vez que é o mais numeroso, com onze participantes. A primeira fase é de conceituação, que define os requisitos de projeto, a fundamentação teórica, o recorte geográfico e as metodologias a serem empregadas durante todo o processo. A divisão se dá em subgrupos de três a quatro participantes, ao passo em que o grupo 
maior ainda se reúne esporadicamente, seja nas discussões em sala ou na pesquisa de campo, de modo a unificar as proposições ao conceito que é memória, percurso de acolhimento na geração de pertencimento por meio da ocupação de espaços públicos. Simultaneamente, há subgrupos distintos daqueles supracitados com o objetivo de criar dispositivos gráficos de organização dos dados coletados, como mapas, tabelas e o próprio processo do grande grupo.

Figura 5 - Primeira Configuração do Grupo A

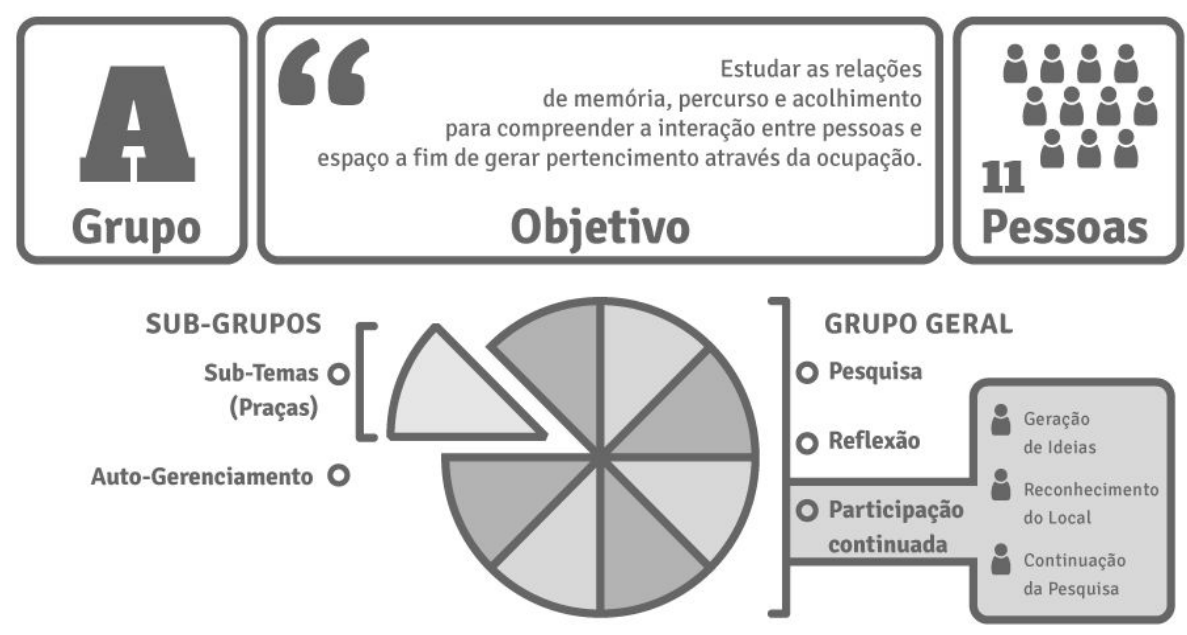

Fonte: Os autores (2017)

Figura 6 - Ferramentas utilizadas pelo Grupo A

\section{Ferramentas}
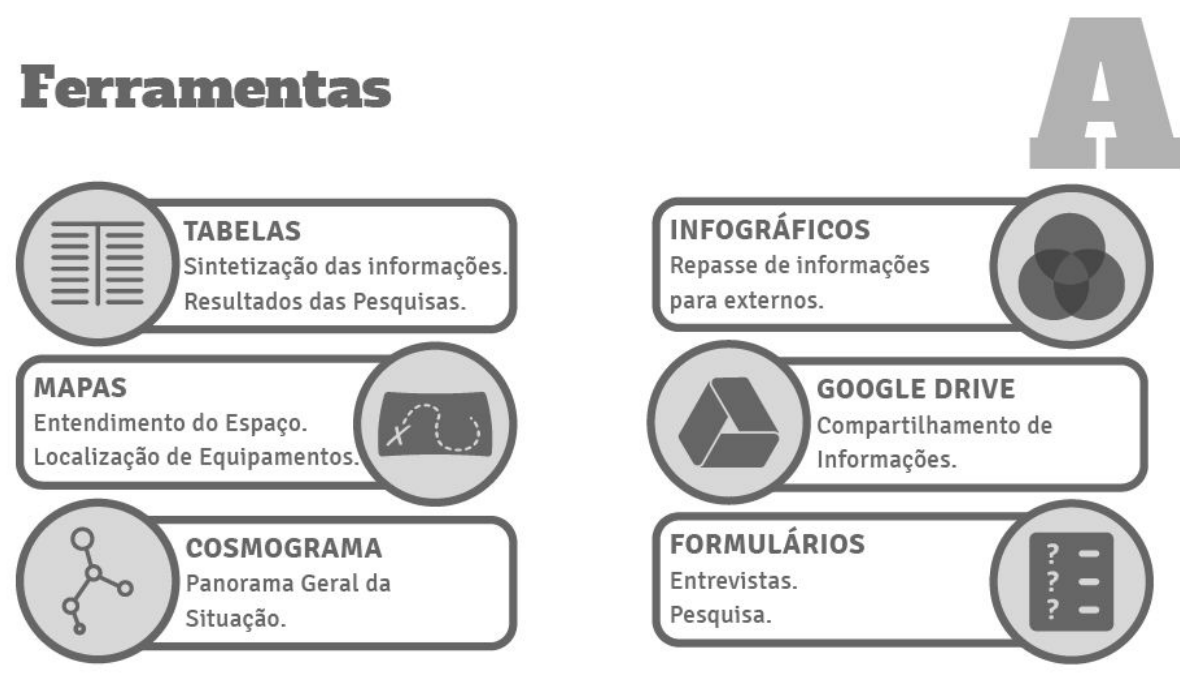

Fonte: Os autores (2017) 
Figura 7 - Linha do tempo do Grupo A

\section{Linha do Tempo}

Mapeamento

Relação Pessoa

+ Cidade
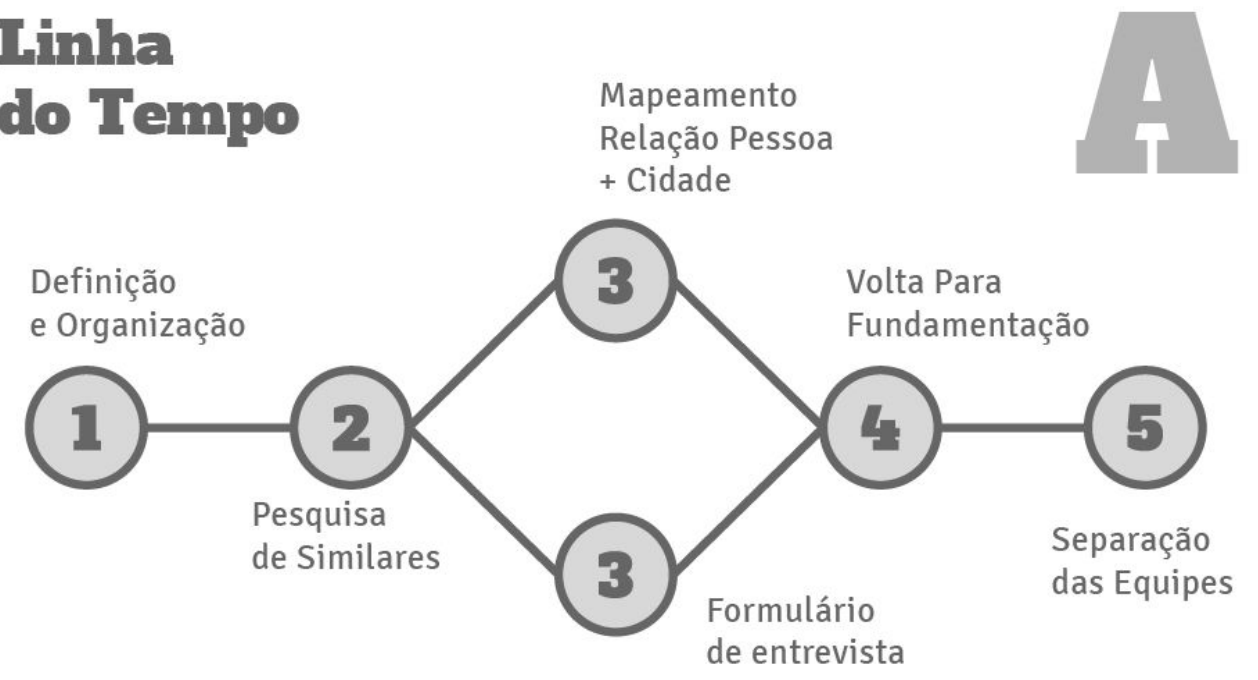

Fonte: Os autores (2017)

O grupo B possui apenas três participantes e, embora conte com uma fase de pesquisa e discussão coletiva que estrutura o tema e define o interesse comum e a fundamentação teórica, se propõe como três projetos independentes e distintos. Com o embasamento comum aos três participantes, cada um define seu recorte do tema central, a cidade como linguagem, e passa a executar o que vem a ser sua proposta por conta própria. Na segunda fase, o câmbio de informações entre os membros, agora agentes independentes, já não é inerente aos processos que conduzem as propostas finais.

Figura 8 - Primeira configuração do grupo B

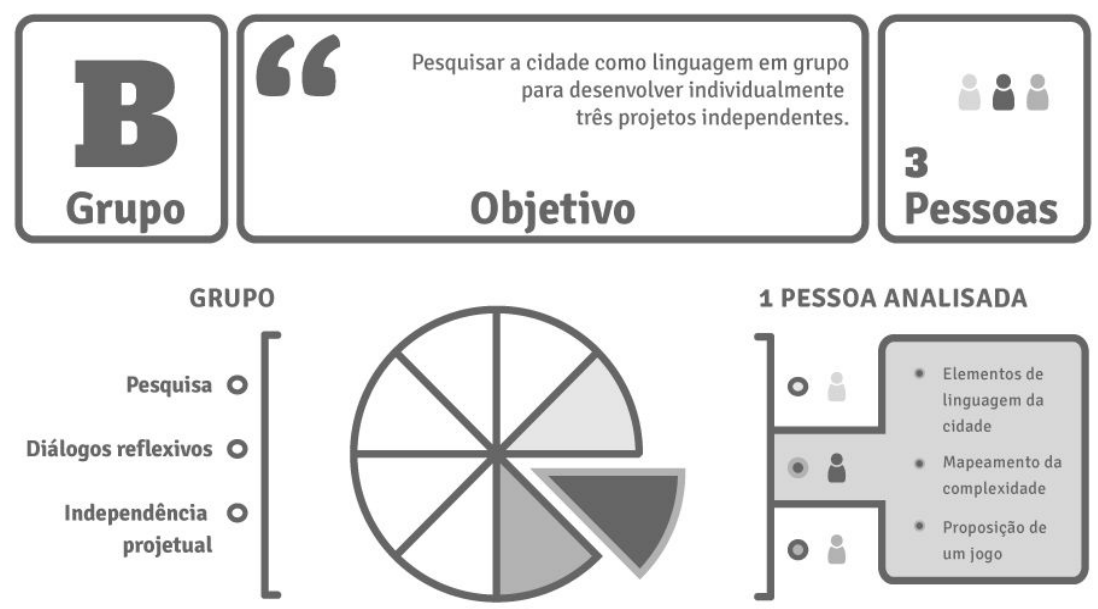

Fonte: Os autores (2017) 
Figura 9 - Ferramentas utilizadas pelo Grupo B

\section{Ferramentas}
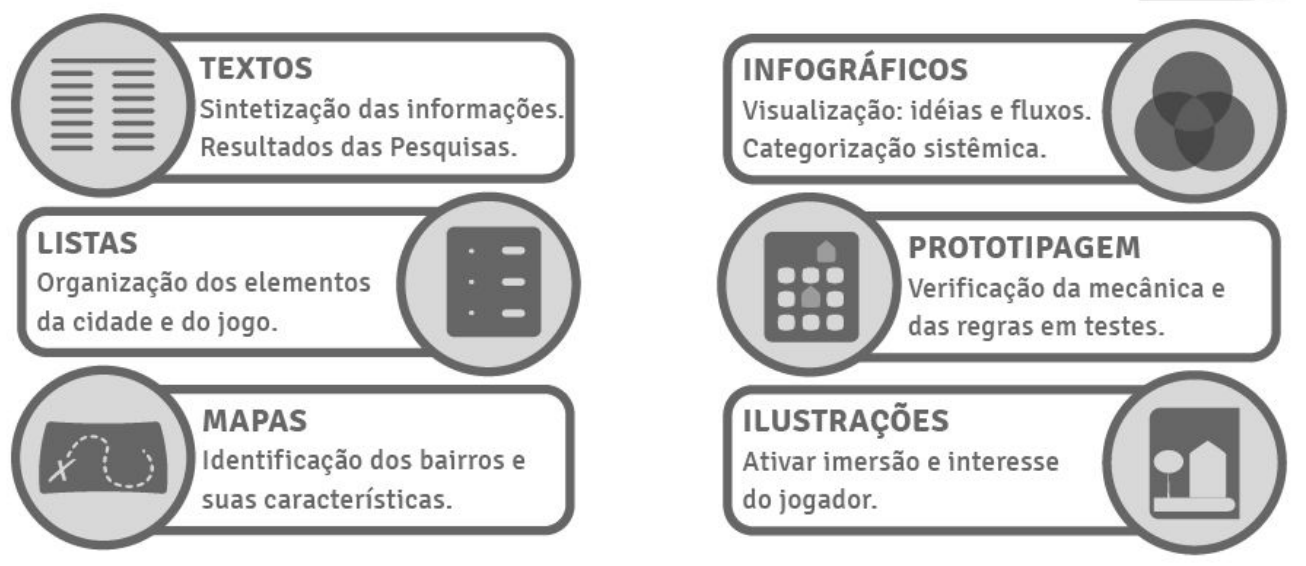

Fonte: Os autores (2017)

Figura 10 - Linha do tempo do Grupo B

\section{Ininha do Tempo}

Mapeamento

Relação Pessoa

+ Cidade
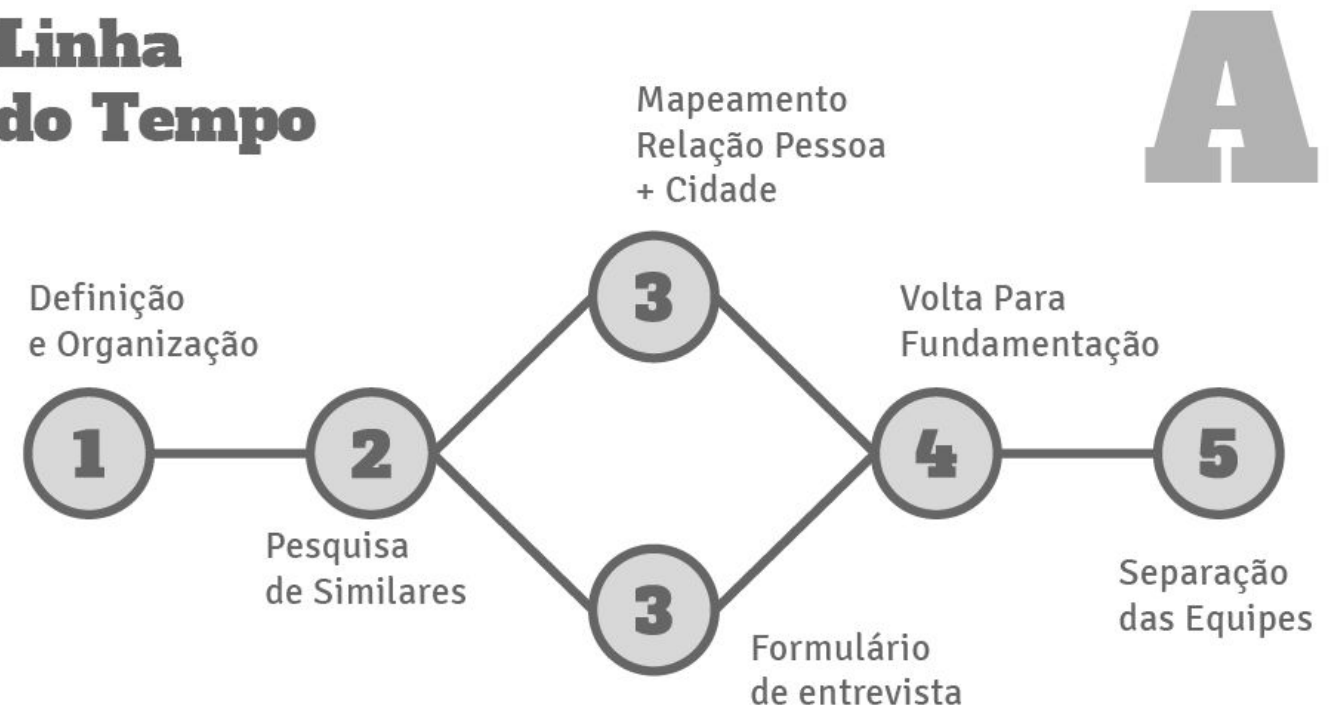

Fonte: Os autores (2017)

\section{Conclusão}

Como dito, a metadisciplina reflete sobre si mesma e se reflete. Sob o ponto de vista externo as condições do ambiente onde se constrói e partilha o conhecimento determinam as diretrizes da pesquisa. A experiência de Projeto de Produto 4 expôs o cenário da construção de 
conceitos intrinsecamente ligada ao fazer design, pesquisar design, aprender e ensinar através do design; produzir conhecimento e trazer aspectos sociais para sala de aula de modo que o produto esteja muito além das produções dos alunos, por constituir interações e experimentos, que gradativamente se sedimentam sensorial, emocional e cognitivamente. Estes aspectos oferecem meios a reflexões teóricas acerca do design no processo didático. Metadisciplina, metadesign, metaprojeto se fundamentam na auto-reflexão e trazem muitos aspectos comuns e complementares em termos metodológicos e objetivos. Entender a metadisciplina como uma metodologia de ensino implica valorizar saberes individuais, evocar o protagonismo estudantil, favorecer a autonomia, a autogestão e trazer deliberadamente o design para a educação. A abrangência holistica da metadisciplina explora a potencialidade do designer aprendiz como articulador de um sistema complexo de influências mútuas e conhecimentos, prévios e adquiridos, como no metadesign (MORAES, 2010), que lhe serve guia e autonomia em suas escolhas na atividade projetual, como observamos nos resultados do estudo de caso apresentado: um processo em que novas configurações são produzidas nas interfaces da comunicação, aprendizagem, produção de sentido e troca de saberes, que oferecem elementos ao prosseguimento da investigação à construção de diretrizes conceituais.

A conectividade entre interesses individuais e consensos coletivos no desenvolvimento de uma disciplina ou na resolução de um problema favorece as partilhas, a descoberta de novos sentidos, a construção de vínculos e o autoconhecimento. Não é um processo fácil. Não é pressuposto que se chega ao consenso. Existem desafios na aplicação de abordagens disruptivas no contexto dos métodos tradicionais de ensino e aprendizagem e de projeto em design. No entanto, a intersecção dessas áreas dá voz aos diversos pontos de vistas que podem ser agregados e combinados na produção de uma miríade de soluções relevantes e inovadoras no ensino e no design. No ponto de vista do aluno-pesquisador Victor Furtado: "a metadisciplina é um grande globo de espelhos de raios centrífugos-magnéticos cujos reflexos saem do globo, perpassam por todo um caminho, mas magneticamente são mais uma vez atraídos para dentro desse globo que vai digeri-los pela enésima vez para definir qual será a próxima trajetória dos mesmos".

A pesquisa-ação e a busca de diretrizes da metadisciplina indicam, desde o início da pesquisa em 2014, que os trabalhos interdisciplinares, com o protagonismo discente e o compartilhamento de saberes como requisitos de toda a produção de conhecimento revelam uma nova forma de se propor o ensino e a aprendizagem. E é nessa forma que o design como fundamento e ferramenta nos permite aprimorar a travessia nessa trajetória que ainda, e sempre, está em construção.

\section{Referências Bibliográficas}

ACASO, Maria; MANZANERA, Paloma. Eso no es una clase. Madrid: Telefonica; Barcelona: Ariel, 2015.

FREIRE, Paulo. Pedagogia da autonomia: saberes necessários à prática educativa. Rio de Janeiro: Paz e Terra, 2015.

Educação como Prática da Liberdade. Rio de Janeiro: Paz e Terra, 1967.

IDEO. HCD - Human Centered Design: Kit de ferramentas. EUA: Ideo, 2009. 102 p. Disponível em: <http://www.ideo.com/work/human-centered-design-toolkit/>. Acessado em julho de 2013.

JOHNSON, David W; JOHNSON, Roger T; SMITH, Karl A. A Aprendizagem Cooperativa Retorna às 
Faculdades: Qual é a Evidência de que Funciona? in Change, Jul/Aug98, Vol. 30, Issue 4.

KHÖLER, Elizabeth; BAUM, Carlos. Desdobrando a teoria Ator-rede: Reagregando o social no trabalho de Bruno Latour. Polis e Psique, Porto Alegre, v.3, n.1, p.142-157. 2013.

KRIPPENDORFF, Klaus. Design Centrado no ser humano: uma necessidade cultural. Tradução Gabrielle Meireles. Estudos em Design. Rio de Janeiro: Associação de Ensino de Design do Brasil, v. 8, n. 3, p. 87-98, setembro de 2000.

LATOUR, Bruno. Um Prometeu cauteloso?: alguns passos rumo a uma filosofia do design (com especial atenção a Peter Sloterdijk). Agitprop: revista brasileira de design, São Paulo, v.6, n.58, jul/ago. 2014.

MANZINI, E. Design para Inovação Social e Sustentabilidade: Comunidades Criativas, organizações colaborativas e novas redes projetuais. Tradução: Carla Cipolla. Rio de Janeiro: E-papers, 2008

Design: quando todos fazem design, uma introdução ao design para inovação social. Trad. Luzia Araujo. São Leopoldo RS: Ed. Unisinos, 2017.

MARGOLIN, Victor; MARGOLIN, Sylvia. Um Modelo Social de Design: questões de prática e pesquisa. Tradução: Paulo Fernando de Almeida Souza. Revista Design em Foco, vol. I, núm. 1, julho-dezembro, 2004, pp. 43-48, Universidade do Estado da Bahia. Disponível em: http://www.redalyc.org/articulo.oa?id=66110105. Consultado em: 22/03/2015.

MORAES, Dijon. Metaprojeto: o design do design. São Paulo: Blucher, 2010.

PAPANEK, Victor J. Design for the Real World. Thames and Hudson. Universidade da Califórnia, 1977.

RANCIÈRE, Jacques. O Espectador Emancipado. Tradução Daniele Ávila - Questão de Crítica, 2008. Disponível em: <http://www.questaodecritica.com.br/2008/05/o-espectador-emancipado>. Acesso em: 29 abr. 2013.

SAVIANI, D. A Filosofia da educação e o problema da inovação em educação. In: GARCIA, W. E. (org.). Inovação Educacional no Brasil: problemas e perspecMvas. São Paulo, Cortez Editora, 1995.

SCHÖN, Donald. Educando o profissional reflexivo: um novo design para o ensino e a aprendizagem. São Paulo: Artmed, 2000.

TOLEDO, R. F.; JACOBI, P. R. Pesquisa-ação e educação: compartilhando princípios na construção de conhecimentos e no fortalecimento comunitário para o enfrentamento de problemas.

Educação \& Sociedade, Revista de Ciência da Educação. CEDES, Campinas, v. 34, n. 122, p. 155-173, jan.-mar. 2013.

THIOLLENT, Michel. Metodologia da Pesquisa-Ação. São Paulo: Cortez,1985.

TORRES, Patrícia Lupion. Laboratório on-line de aprendizagem: uma proposta crítica de aprendizagem colaborativa para a educação. Tubarão: Ed. Unisul, 2004.

TRIPP, David. Pesquisa Ação: uma Introdução Metodológica. Tradução Lélio Lourenço de Oliveira. Educação e Pesquisa, São Paulo, v. 31, n. 3, p. 443-466, set./dez. 2005.

VASSÃO, Caio Adorno. Metadesign: ferramentas, estratégias e ética para a complexidade. São Paulo: Blucher, 2010. (Coleção Pensando o Design). 